\title{
Roxadustat Treatment of Chronic Kidney Disease- Associated Anemia in Japanese Patients Not on Dialysis: A Phase 2, Randomized, Double-Blind, Placebo-Controlled Trial
}

Tadao Akizawa · Manabu Iwasaki · Tetsuro Otsuka · Michael Reusch •

Toshihiro Misumi

Received: January 9, 2019 / Published online: April 5, 2019

(c) The Author(s) 2019

\section{ABSTRACT}

Introduction: This study evaluated efficacy and safety/tolerability of roxadustat, an oral hypoxia-inducible factor prolyl hydroxylase inhibitor, in Japanese anemic non-dialysis-dependent chronic kidney disease (NDD-CKD) patients.

Methods: In this phase 2, double-blind, 24-week study, NDD-CKD patients were randomized to oral placebo or roxadustat $(50,70$, or $100 \mathrm{mg}$ ) three times weekly (TIW) for 6 weeks

Enhanced Digital Features To view enhanced digital features for this article go to https://doi.org/10.6084/ m9.figshare.7880417.

Electronic supplementary material The online version of this article (https://doi.org/10.1007/s12325019-00943-4) contains supplementary material, which is available to authorized users.

Toshihiro Misumi was formerly employed at Astellas Pharma Inc.

T. Akizawa (ه)

Showa University School of Medicine, Namics 301,

4-24-51 Takanawa, Minato-ku, Tokyo, Japan

e-mail: akizawa@med.showa-u.ac.jp

M. Iwasaki

Yokohama City University School of Data Science,

Yokohama, Japan

T. Otsuka

Japan/Asia Clinical Development 2, Astellas Pharma

Inc., Tokyo, Japan followed by dose adjustments to maintain hemoglobin $(\mathrm{Hb})$ at $10-12 \mathrm{~g} / \mathrm{dL}$ for 18 weeks; patients meeting pre-defined criteria were rerandomized to TIW or once-weekly dosing. The primary end point was rate of rise of $\mathrm{Hb}(\mathrm{g} / \mathrm{dL} /$ week) during the first 6 weeks; secondary end points included response rate $(\mathrm{Hb} \geq 10.0 \mathrm{~g} / \mathrm{dL}$ and increase in $\mathrm{Hb}$ from baseline $\geq 1 \mathrm{~g} / \mathrm{dL}$ ) and mean $\mathrm{Hb}$ and change from baseline in $\mathrm{Hb}$ at weeks 18-24. The main safety outcomes were vital signs, laboratory test results, electrocardiograms, and frequency of treatment-emergent adverse events.

Results: Of 107 patients randomized, 83 completed the study. The mean (SD) rate of rise of $\mathrm{Hb}$ during the first 6 weeks was - $0.052(0.142)$ for placebo and +0.200 (0.160), +0.453 $(0.256)$, and $+0.570(0.240)$ for roxadustat $50-$, 70-, and 100-mg TIW groups, respectively $(p<0.001)$. Response rate was $14.8 \%$ for placebo and $81.5 \%, 100 \%$, and $100 \%$ for roxadustat TIW groups $(p<0.001)$. Change in $\mathrm{Hb}$ from baseline at weeks 18-24 was $-0.17(0.61)$ for

M. Reusch

Medical Science Urology and Nephrology, Astellas Pharma Europe B.V., Leiden, The Netherlands

T. Misumi Japan-Asia Data Science, Astellas Pharma Inc., Tokyo, Japan 
placebo and $+1.10(0.71),+1.33(0.82)$, and $+1.55(0.88) \mathrm{g} / \mathrm{dL}$ for roxadustat TIW groups $(p<0.001)$. No deaths or major adverse cardiac events occurred with roxadustat.

Conclusion: Roxadustat was well tolerated and effective in correcting Hb levels within 6 weeks in Japanese anemic NDD-CKD patients.

Trial registration: ClinicalTrials.gov: NCT01964196. Registered 15 October 2013 (retrospectively registered).

Funding: Astellas Pharma Inc.

Keywords: Anemia; CKD; Clinical trial; Hemoglobin; Nephrology; Roxadustat

\begin{tabular}{|c|c|}
\hline \multicolumn{2}{|c|}{ Abbreviations } \\
\hline CKD & Chronic kidney disease \\
\hline eGFR & $\begin{array}{l}\text { Estimated glomerular filtration } \\
\text { rate }\end{array}$ \\
\hline $\mathrm{EOF}$ & $\begin{array}{l}\text { Final assessment in the fixed-dose } \\
\text { period }\end{array}$ \\
\hline ESAs & Erythropoiesis-stimulating agents \\
\hline $\mathrm{Hb}$ & Hemoglobin \\
\hline HIF & Hypoxia-inducible factor \\
\hline NDD-CKD & $\begin{array}{l}\text { Non-dialysis-dependent } \\
\text { kidney disease }\end{array}$ \\
\hline QW & Once weekly \\
\hline TEAE & $\begin{array}{l}\text { Treatment-emergent } \\
\text { events }\end{array}$ \\
\hline TIB & Total iron binding capacity \\
\hline TIV & Three times weekly \\
\hline TSA & Transferrin saturation \\
\hline
\end{tabular}

\section{INTRODUCTION}

Anemia is a complication of chronic kidney disease (CKD), associated with reduced quality of life and increased morbidity and mortality $[1,2]$. The standard of care for anemia in CKD comprises recombinant human erythropoietin or its analogs (erythropoiesis-stimulating agents [ESAs]), along with iron supplementation [3]; however, safety concerns associated with the use of high doses of ESAs to achieve higher hemoglobin $(\mathrm{Hb})$ goals limit their use [4-6]. A large study conducted in the USA demonstrated an increased risk of stroke associated with the use of high doses of ESAs in CKD patients with anemia and diabetes [5]. Another study evaluated cardiovascular complications among patients with CKD-associated anemia who were treated with epoetin alfa and reported that targeting a high Hb level (13.5 g/dL) was associated with increased risk of cardiovascular complications and no significant improvement in quality of life compared with targeting a lower $\mathrm{Hb}$ level $(11.3 \mathrm{~g} / \mathrm{dL})$ [6]. Because of these risks associated with currently marketed ESAs, the US Food and Drug Administration mandated that recombinant human erythropoietin dose should be reduced if the rate of rise of $\mathrm{Hb}$ exceeded $1 \mathrm{~g} / \mathrm{dL}$ in any 2-week period.

More recently, an alternative class of therapeutic agents for the treatment of anemia has focused on hypoxia-inducible factor (HIF) [7], and involves activating "early response" target genes that increase endogenous erythropoietin production, while reducing circulating hepcidin and increasing iron bioavailability $[8,9]$. HIF activity is regulated by prolyl hydroxylases, oxygen-sensitive enzymes that target HIF for proteasomal degradation under normal oxygen levels or allow HIF to accumulate during hypoxia [10]. Hypoxiainducible factor prolyl hydroxylase inhibitors inhibit prolyl hydroxylases, thereby mimicking a transient hypoxic state to reduce hepcidin levels and stimulate erythropoiesis $[11,12]$.

Roxadustat (ASP1517, FG-4592, AZD9941) is an orally administered, reversible hypoxia-inducible factor prolyl hydroxylase inhibitor that transiently stabilizes HIF by mimicking an intermittent hypoxic state. Roxadustat is currently in late-stage development for the treatment of anemia in CKD, and has demonstrated efficacy and safety in six phase 2 clinical studies including both non-dialysis-dependent CKD (NDD-CKD) [13-15] and dialysis-dependent CKD [15-17]. Specifically, roxadustat administered three times weekly (TIW) transiently and moderately increased endogenous erythropoietin and $\mathrm{Hb}$ levels and reduced hepcidin in the absence of intravenous iron supplementation. Most recently, a phase 3 study of Chinese patients with CKD and anemia who were on hemo- and peritoneal dialysis reported noninferiority of roxadustat to epoetin alfa in correcting and maintaining $\mathrm{Hb}$ levels (manuscript submitted). The purpose of this study was to 
evaluate the efficacy, safety/tolerability, and dose-response of roxadustat in Japanese patients with anemia and NDD-CKD.

\section{METHODS}

\section{Study Design}

This randomized, parallel-group, double-blind, placebo-controlled, phase 2 study was conducted at 32 sites in Japan from 17 September 2013 (date of first randomization) to 1 December 2015 (date of last evaluation).

The 24-week study consisted of two treatment periods (Fig. 1). The "fixed-dose period" was a 6-week period during which patients were equally randomized 1:1:1:1 (i.e., first randomization) to receive placebo or roxadustat $(50,70$, or $100 \mathrm{mg}$ ) TIW. The subsequent "titration period" was an 18-week period during which dose was adjusted to maintain $\mathrm{Hb}$ at $10-12 \mathrm{~g} / \mathrm{dL}$, taking into consideration the current $\mathrm{Hb}$ level and change in $\mathrm{Hb}$ over the previous 4 weeks. Patients who met pre-defined criteria during the titration period ( $\mathrm{Hb}$ between 11 and $12.5 \mathrm{~g} / \mathrm{dL}$ and an increase of $\geq 1 \mathrm{~g} / \mathrm{dL}$ from baseline) were equally re-randomized 1:1 (i.e., second randomization) to continue TIW treatment or switch to once weekly (QW) dosing as maintenance treatment. The $\mathrm{Hb}$ target range of $11-12.5 \mathrm{~g} / \mathrm{dL}$ was chosen in order to enroll those patients who had improved $\mathrm{Hb}$ levels $(\mathrm{Hb} \geq 11 \mathrm{~g} / \mathrm{dL})$ during the titration period and to exclude those who had temporarily discontinued the drug because of an increase of $\mathrm{Hb}$ levels $>12.5 \mathrm{~g} / \mathrm{dL}$ in accordance with the dose increase/reduction rules. Patients who were rerandomized to roxadustat QW received a twostep increase in dose according to the study drug dose adjustment rule, taking into consideration the current $\mathrm{Hb}$ level and the change in $\mathrm{Hb}$ over the previous 4 weeks.

Dynamic allocation was conducted using a biased-coin minimization approach with the following factors for the first randomization: study site, average $\mathrm{Hb}$ level at screening assessment and screening period, estimated glomerular filtration rate (eGFR) at screening assessment. For the second randomization, the allocation factors were study site, roxadustat dose immediately before the second randomization, and $\mathrm{Hb}$ level at the second randomization.

This study (ClinicalTrials.gov identifier, NCT01964196) was conducted in accordance with the Declaration of Helsinki and was approved by the following institutional review boards: Tokushukai Group Institutional Review Board; Institutional Review Board of Yokosuka Kyosai Hospital; Review Board of Human Rights and Ethics for Clinical Studies; Institutional Review Board of Chubu Rosai Hospital; Institutional Review Board of Kawashima Hospital; Institutional Review Board

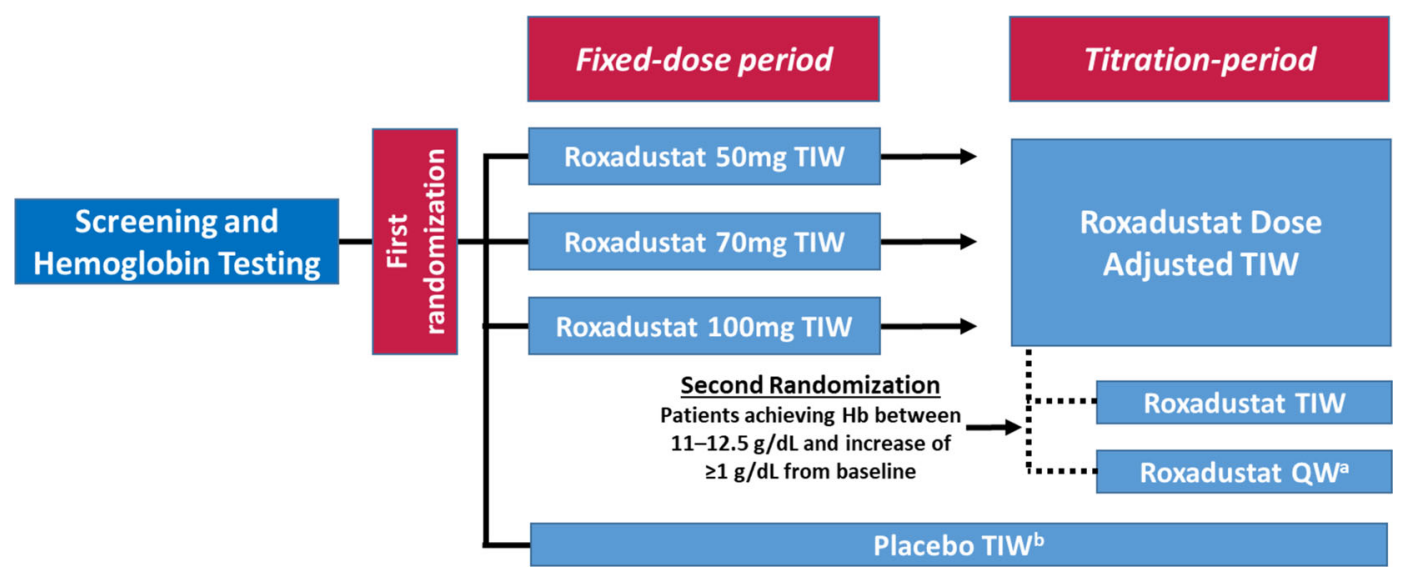

Fig. 1 Patient randomization and treatment protocol. $\mathrm{Hb}$ hemoglobin, QW once weekly, TIW three times weekly. ${ }^{a}$ To maintain blinding, patients took roxadustat $\mathrm{QW}$ and placebo, which was indistinguishable from roxadustat, twice weekly. ${ }^{b}$ In order to maintain blinding, dose adjustment and the second randomization by the web registration system were performed in the placebo arm, but in actuality did not occur 
of Kinashi Obayashi Hospital; Institutional Review Board of Hyogo Prefectural Amagasaki General Medical Center; Institutional Review Board of Rinku General Medical Center; Institutional Review Board of Ehime Prefectural Central Hospital; Institutional Review Board of Juntendo Tokyo Koto Geriatric Medical Center; Institutional Review Board of NTT Medical Center Tokyo; Institutional Review Board of Takikawa Municipal Hospital; National Hospital Organization Central Review Board; Institutional Review Board of Kitamachi clinic; Institutional Review Board of Rakuwakai Otowa Hospital; Institutional Review Board of Fukui Prefectural Hospital; Institutional Review Board of Southern Tohoku Research Institute for Neuroscience; Institutional Review Board of Kitano Hospital; Sapporo Skin Clinic Institutional Review Board; Institutional Review Board of Nagano Red Cross Hospital; Institutional Review Board of Tsuchiura Kyodo General Hospital. All patients provided written informed consent.

\section{Study Participants}

Japanese patients (aged 20-74 years) with anemia associated with NDD-CKD were considered for screening. After informed consent was provided, patients were screened for eligibility within 9 weeks before randomization. Inclusion criteria included eGFR of $\leq 89 \mathrm{~mL} / \mathrm{min} / 1.73 \mathrm{~m}^{2}$ (calculated using the Japanese formula [18]), $\mathrm{Hb}<10 \mathrm{~g} / \mathrm{dL}$ (mean of two Hb levels, one obtained at the screening assessment and one obtained during the $\leq 9$-week screening period), body weight $\geq 40 \mathrm{~kg}$ and $<80 \mathrm{~kg}$, transferrin saturation (TSAT) $\geq 5 \%$, serum ferritin $\geq$ $30 \mathrm{ng} / \mathrm{mL}$, folate $\geq 4 \mathrm{ng} / \mathrm{mL}$, and vita$\min B_{12} \geq 180 \mathrm{pg} / \mathrm{mL}$. Patients were excluded if they had received ESA within 6 weeks before screening. The concomitant use of oral iron was allowed; intravenous iron was permitted only if TSAT was $<5 \%$ and serum ferritin was $<30 \mathrm{ng} /$ $\mathrm{mL}$. Full exclusion criteria are described in the Supplementary Material.

\section{Study Drug}

Roxadustat (ASP1517; Astellas Pharma Inc.) was provided as 20- and 50-mg capsules. A double- blinding procedure for participants, care providers, and those assessing outcomes ensured that oral roxadustat and placebo capsules were indistinguishable in appearance and all treatments were coded.

\section{Assessments and End Points}

The primary efficacy end point was the rate of rise in $\mathrm{Hb}(\mathrm{g} / \mathrm{dL} /$ week) from baseline to the final assessment in the fixed-dose period (EOF). The rate of rise was calculated as the slope of a linear regression for each patient using all $\mathrm{Hb}$ data collected during the fixed-dose period. The primary end point was determined on the basis of regulatory feedback to quantify the rate of rise in $\mathrm{Hb}$ with various starting doses of roxadustat. Secondary efficacy end points included mean $\mathrm{Hb}$ at weeks 18-24 (average of weeks 18-24), change in $\mathrm{Hb}$ from baseline to the mean of weeks $18-24$, and cumulative response rate (i.e., $\mathrm{Hb}$ level $\geq 10.0 \mathrm{~g} / \mathrm{dL}$ and an increase in $\mathrm{Hb}$ from baseline of $\geq 1 \mathrm{~g} / \mathrm{dL}$ ) over the entire treatment period. Mean-standard deviation (SD) plots were compiled for $\mathrm{Hb}$ at baseline and at each study visit week: (1) from baseline through the overall 24-week treatment period, stratified by dose during the fixed-dose period (i.e., first randomization), and (2) from the start of re-randomization, stratified by dose frequency during the titration period (i.e., second randomization).

Exploratory end points included mean weekly ferritin, TSAT, hepcidin, total iron binding capacity (TIBC), transferrin, and erythropoietin levels during the overall treatment period. Clinical laboratory analyses (ferritin, TSAT, TIBC, transferrin, ceruloplasmin, erythropoietin, and cholesterol) were performed by SRL Medisearch Inc. (Tokyo, Japan); measurement of hepcidin was performed by Astellas Pharma Europe BV using a validated liquid chromatography-tandem mass spectrometry method with a TSQ Quantum Ultra mass spectrometer (Thermo Fisher, Waltham, MA, USA). The calibration range was $1.5-192 \mathrm{ng} / \mathrm{mL}$ and serum samples of $300 \mu \mathrm{L}$ were used. Intra- and inter-assay precision (coefficient of variation) ranged between $2.5 \%$ and $16.5 \%$ and intra- and 
inter-assay accuracy ranged between $-0.7 \%$ and $25.3 \%$.

Safety/tolerability was assessed as the occurrence of treatment-emergent adverse events (TEAEs), vital signs (blood pressure and pulse rate), clinical laboratory evaluations, and standard 12-lead electrocardiogram. TEAEs were coded using the Medical Dictionary for Regulatory Activities version 15.1 terminology.

\section{Statistical Analysis}

A sample size of 25 patients per group (100 patients in total, considering withdrawals) was determined for the number of patients to be treated with roxadustat to achieve $\geq 80 \%$ power for establishing the superiority of roxadustat $50 \mathrm{mg}$ TIW to placebo TIW. This was based on a simulation $(10,000$ repetitions and two-sided 0.05 significance level) with phase $2 \mathrm{a}$ data of change in $\mathrm{Hb}$ at week 4 (null hypothesis that rate of rise in $\mathrm{Hb}$ is equivalent between placebo TIW and roxadustat $50 \mathrm{mg}$ TIW) where the mean (SD) rate of rise would be 0.0 $(0.108) \mathrm{g} / \mathrm{dL}$ and $0.21(0.292) \mathrm{g} / \mathrm{dL}$ in the placebo and roxadustat 50-mg TIW groups, respectively.

The primary efficacy analysis was performed on the full analysis set, defined as patients who received at least one dose of study drug and who had data of at least one efficacy variable (i.e., $\mathrm{Hb})$ measured after the start of treatment. The following closed procedure was used for multiplicity adjustment in the analysis of primary efficacy analysis: step 1, compare roxadustat $100 \mathrm{mg}$ with placebo; step 2 , compare roxadustat $70 \mathrm{mg}$ with placebo; step 3, compare roxadustat $50 \mathrm{mg}$ with placebo. This analysis was conducted using an analysis of covariance (ANCOVA) model with first randomizationbased treatment group (roxadustat 50, 70, and $100 \mathrm{mg}$ TIW, and placebo TIW) as the factor, and $\mathrm{Hb}$ level (at baseline) and eGFR (at the screening assessment) as covariates. Safety analysis was performed on the safety analysis set, defined as patients who received at least one dose of study drug. Other efficacy end points, exploratory assessments, and safety assessments were analyzed using descriptive statistics.
Statistical tests were conducted with a two-sided 0.05 significance level. All results are presented as mean \pm SD. $p$ values for post hoc exploratory analyses were calculated from intergroup twosample $t$ tests comparing the pooled roxadustat change from baseline with placebo change from baseline.

\section{RESULTS}

\section{Patient Demographics and Baseline Characteristics}

Of 190 patients who were screened, 107 were randomized to placebo TIW $(n=27)$ or roxadustat $50 \mathrm{mg}$ TIW $(n=27), 70 \mathrm{mg}$ TIW $(n=26)$, or $100 \mathrm{mg}$ TIW $(n=27)$ groups; 56 patients met criteria for re-randomization during the titration period and received roxadustat QW $(50 \mathrm{mg}, n=7 ; 70 \mathrm{mg}, n=12,100 \mathrm{mg}$, $n=8$ ) or TIW (50 mg, $n=7 ; 70 \mathrm{mg}, n=12$, $100 \mathrm{mg}, n=9$ ); 1 patient in the placebo TIW group met criteria for re-randomization and continued placebo TIW. A total of 83 (77.6\%) patients completed the 24-week study. The overall discontinuation rate was $40.7 \%$ for the placebo TIW group and $16.3 \%$ for the roxadustat TIW pooled group (50 $\mathrm{mg}, n=9$ [33.3\%]; $70 \mathrm{mg}, n=0 ; 100 \mathrm{mg}, n=4$ [14.8\%]). Patients discontinued as a result of a TEAE $(n=7,8.8 \%$ roxadustat TIW pooled; $n=2,7.4 \%$ placebo TIW), progressive disease ( $n=4,5.0 \%$ roxadustat TIW pooled), $\mathrm{Hb}$ level $<8 \mathrm{~g} / \mathrm{dL} \quad(n=5$, $18.5 \%$ placebo TIW), lack of efficacy $(n=4$, $14.8 \%$ placebo TIW), withdrawal by patient ( $n=1,1.3 \%$ roxadustat TIW pooled), or other reason $(n=1,1.3 \%$ roxadustat TIW pooled) (Fig. 2).

Baseline demographics were similar between groups (Table 1). Mean eGFR levels were low $\left(16.3 \mathrm{~mL} / \mathrm{min} / 1.73 \mathrm{~m}^{2}\right)$ for both placebo TIW and roxadustat TIW groups, with half of patients having baseline eGFR below $15 \mathrm{~mL} /$ $\min / 1.73 \mathrm{~m}^{2}$. No patients had eGFR above $60 \mathrm{~mL} / \mathrm{min} / 1.73 \mathrm{~m}^{2}$. 


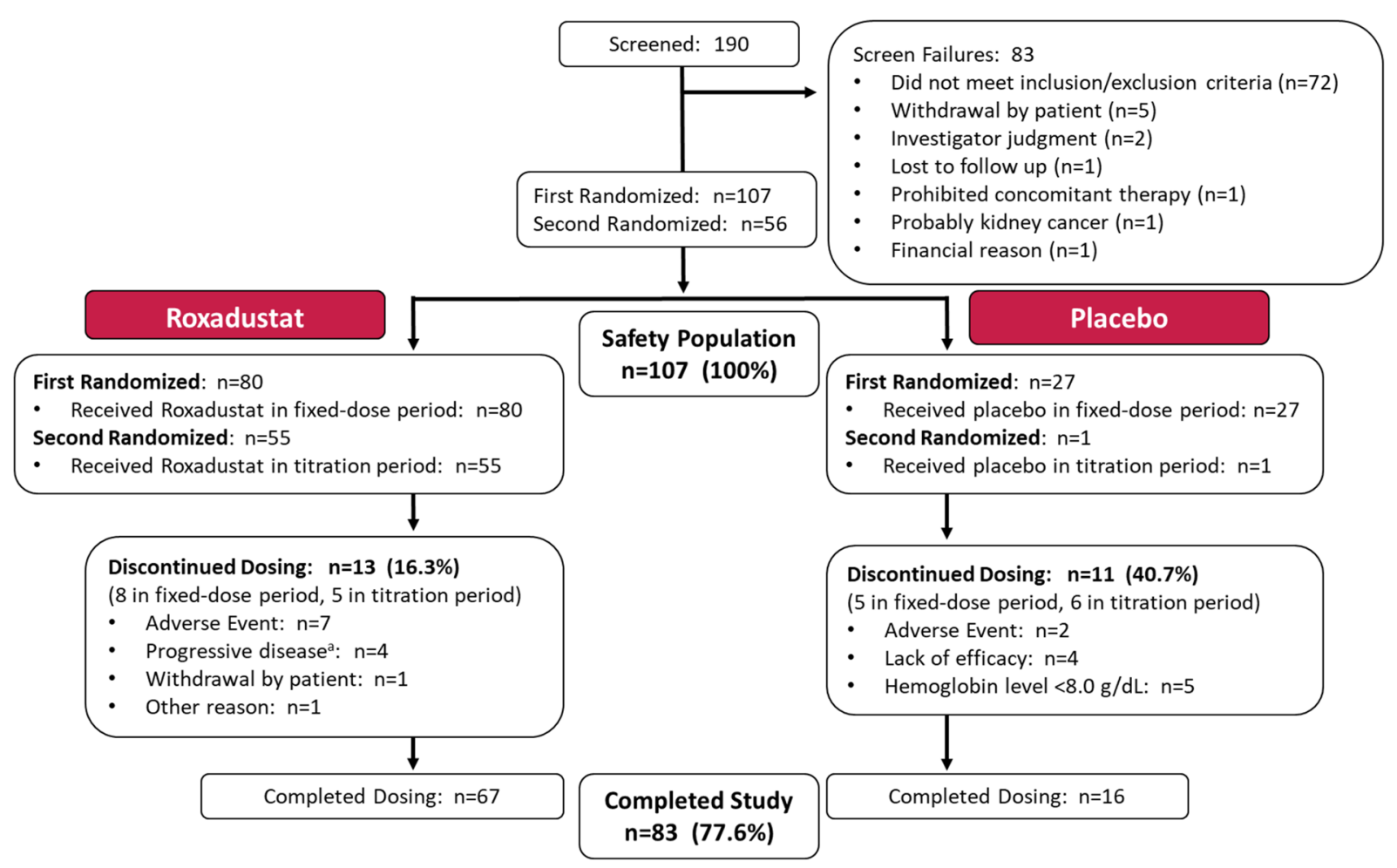

Fig. 2 Patient disposition. ${ }^{a}$ Discontinuation due to progressive disease requiring initiation of dialysis occurred in three patients [11.1\%] in the 50-mg TIW group and one patient [3.7\%] in the 100-mg TIW group. All four patients

\section{Primary End Point}

Compared with the placebo TIW group, the mean rate of rise in $\mathrm{Hb}(\mathrm{g} / \mathrm{dL} /$ week) from baseline to EOF was significantly greater in all roxadustat TIW groups ( $p<0.001$; Fig. 3$)$, with an unadjusted mean (SD) of 0.200 (0.160), 0.453 (0.256), and $0.570(0.240)$ for roxadustat 50-, 70-, and 100-mg TIW groups, respectively, compared with $-0.052(0.142)$ for placebo TIW. The rate of rise in $\mathrm{Hb}$ in the roxadustat TIW pooled group was 0.407 (0.270). A post hoc analysis assessed the change in $\mathrm{Hb}$ from baseline to week 2 and from week 2 to week 4; results are presented in Table 2 .

\section{Secondary Efficacy End Points}

The mean (SD) Hb level (g/dL) at weeks 18-24 was $9.42(0.84)$ for placebo TIW and 10.48 (0.64), $10.72(0.56)$, and $10.88(0.66)$ for the had baseline eGFR $\leq 10 \mathrm{~mL} / \mathrm{min} / 1.73 \mathrm{~m}^{2}$. All four cases were considered to be consistent with the natural progression of disease and therefore unrelated to the study drug

roxadustat 50-, 70-, 100-mg TIW groups, respectively, and $10.71(0.63)$ for the roxadustat TIW pooled group. The mean (SD) change in $\mathrm{Hb}$ $(\mathrm{g} / \mathrm{dL})$ from baseline to the mean of weeks 18-24 was significantly greater than the placebo TIW group with all roxadustat dose groups (placebo - 0.17 [0.61]; $50 \mathrm{mg}, 1.1$ [0.71]; $70 \mathrm{mg}$, 1.33 [0.82]; $100 \mathrm{mg}, 1.55$ [0.88]; $p<0.001$ ).

The cumulative response rate over the entire treatment period was $14.8 \%$ for the placebo TIW group and $81.5 \%, 100 \%$, and $100 \%$ for roxadustat 50, 70, and $100 \mathrm{mg}$ TIW, respectively $(p<0.001)$; overall response rate for roxadustat TIW pooled was $93.8 \%(p<0.001)$.

When stratified by dose during the fixeddose period (i.e., first randomization), mean $\mathrm{Hb}$ level increased from baseline in a dose-dependent manner; mean $\mathrm{Hb}$ levels remained within the target range of $10-12 \mathrm{~g} / \mathrm{dL}$ in all roxadustat groups during the titration period (Fig. 4a). A gradual decrease in $\mathrm{Hb}$ was observed following 
Table 1 Patient demographics, relevant medical history, and baseline characteristics

\begin{tabular}{|c|c|c|c|c|c|}
\hline Variable & $\begin{array}{l}\text { Placebo TIW } \\
(n=27)\end{array}$ & $\begin{array}{l}\text { Roxadustat } 50 \text { mg } \\
\text { TIW starting dose } \\
(n=27)\end{array}$ & $\begin{array}{l}\text { Roxadustat } 70 \mathrm{mg} \\
\text { TIW starting dose } \\
(n=26)\end{array}$ & $\begin{array}{l}\text { Roxadustat } 100 \mathrm{mg} \\
\text { TIW starting dose } \\
(n=27)\end{array}$ & $\begin{array}{l}\text { Roxadustat } \\
\text { TIW pooled } \\
(n=80)\end{array}$ \\
\hline Age (year) & $61.9(10.6)$ & $67.3(7.7)$ & $60.8(8.8)$ & $65.0(8.5)$ & $64.4(8.7)$ \\
\hline Male sex, $n(\%)$ & $11(40.7)$ & $14(51.9)$ & $14(53.8)$ & $11(40.7)$ & $39(48.8)$ \\
\hline Body weight $(\mathrm{kg})^{a}$ & $60.17(8.72)$ & $59.88(9.32)$ & $59.70(10.09)$ & $57.64(10.28)$ & $59.07(9.83)$ \\
\hline \multicolumn{6}{|c|}{ Primary disease of CKD, $n(\%)$} \\
\hline $\begin{array}{l}\text { Chronic } \\
\text { glomerulonephritis }\end{array}$ & $4(14.8)$ & $8(29.6)$ & $6(23.1)$ & $7(25.9)$ & $21(26.3)$ \\
\hline $\begin{array}{l}\text { Diabetic } \\
\text { nephropathy }\end{array}$ & $11(40.7)$ & $11(40.7)$ & $10(38.5)$ & $12(44.4)$ & $33(41.3)$ \\
\hline $\begin{array}{l}\text { Chronic } \\
\text { pyelonephritis }\end{array}$ & 0 & 0 & 0 & $1(3.7)$ & $1(1.3)$ \\
\hline $\begin{array}{l}\text { Polycystic kidney } \\
\text { disease }\end{array}$ & $4(14.8)$ & 0 & $3(11.5)$ & $2(7.4)$ & $5(6.3)$ \\
\hline Nephrosclerosis & $6(22.2)$ & $5(18.5)$ & $5(19.2)$ & $4(14.8)$ & $14(17.5)$ \\
\hline Other & $2(7.4)$ & $3(11.1)$ & $2(7.7)$ & $1(3.7)$ & $6(7.5)$ \\
\hline $\begin{array}{l}\text { History of iron } \\
\text { deficiency } \\
\text { anaemia, } n(\%)\end{array}$ & $1(3.7)$ & 0 & $2(7.7)$ & $2(7.4)$ & $4(5.0)$ \\
\hline $\begin{array}{l}\text { Concomitant iron } \\
\text { therapy (oral) use }\end{array}$ & $7(25.9)$ & $10(37.0)$ & $8(30.8)$ & $9(33.3)$ & $27(33.8)$ \\
\hline Folate $(\mathrm{nmol} / \mathrm{L})$ & $19.97(8.13)$ & $18.76(7.16)$ & $17.57(6.88)$ & $18.18(6.93)$ & $18.19(6.92)$ \\
\hline $\begin{array}{l}\text { Vitamin B12 (pmol/ } \\
\text { L) }\end{array}$ & $402.2(244.6)$ & $363.3(157.4)$ & $282.9(118.3)$ & $309.2(203.0)$ & $317.7(165.1)$ \\
\hline $\begin{array}{l}\mathrm{eGFR}^{\mathrm{c}}(\mathrm{mL} / \mathrm{min} / \\
\left.1.73 \mathrm{~m}^{2}\right)\end{array}$ & $16.3(8.5)$ & $15.8(6.3)$ & $17.3(9.5)$ & $15.9(7.5)$ & $16.3(7.8)$ \\
\hline$(\min , \max )$ & $6.0,40.0$ & $8.0,28.0$ & $7.0,47.0$ & $8.0,31.0$ & $7.0,47.0$ \\
\hline Hemoglobin $(\mathrm{g} / \mathrm{dL})$ & $9.3(0.7)$ & $9.4(0.6)$ & $9.4(0.6)$ & $9.4(0.5)$ & $9.4(0.6)$ \\
\hline$(\min , \max )$ & $7.9,10.7$ & $7.3,10.2$ & $7.9,10.4$ & $8.1,10.1$ & $7.3,10.4$ \\
\hline Ferritin $(\mathrm{ng} / \mathrm{mL})$ & $125.4(74.1)$ & $119.7(61.0)$ & $144.4(99.7)$ & $129.8(89.3)$ & $131.1(84.2)$ \\
\hline$(\min -\max )$ & $(22.1-304.0)$ & $(28.0-277.0)$ & $(39.4-400.0)$ & $(29.2-380.0)$ & $(28.0-400.0)$ \\
\hline TSAT (\%) & $26.8(10.6)$ & $28.3(8.2)$ & $29.7(10.0)$ & $31.1(11.8)$ & $29.7(10.0)$ \\
\hline$(\min -\max )$ & $(12.5-58.1)$ & $(12.4-50.0)$ & $(15.5-65.9)$ & $(10.4-62.0)$ & $(10.4-65.9)$ \\
\hline Hepcidin (ng/mL) & $40.9(26.2)$ & $37.8(21.3)$ & $45.9(25.8)$ & $36.3(23.3)$ & $39.9(23.6)$ \\
\hline$(\min -\max )$ & $(7.07-105.00)$ & $(5.93-83.60)$ & $(11.30-94.87)$ & $(7.40-103.20)$ & $(5.93-103.20)$ \\
\hline
\end{tabular}


Table 1 continued

\begin{tabular}{llllll}
\hline Variable & $\begin{array}{l}\text { Placebo TIW } \\
(\boldsymbol{n}=27)\end{array}$ & $\begin{array}{l}\text { Roxadustat } 50 \mathbf{~ m g} \\
\text { TIW starting dose } \\
(\boldsymbol{n}=27)\end{array}$ & $\begin{array}{l}\text { Roxadustat 70 mg } \\
\text { TIW starting dose } \\
(\boldsymbol{n}=26)\end{array}$ & $\begin{array}{l}\text { Roxadustat 100 mg } \\
\text { TIW starting dose } \\
(\boldsymbol{n}=\mathbf{2 7})\end{array}$ & $\begin{array}{l}\text { Roxadustat } \\
\text { TIW pooled } \\
(\boldsymbol{n}=\mathbf{8 0})\end{array}$ \\
\hline TIBC $(\mu \mathrm{mol} / \mathrm{L})$ & $45.4(4.8)$ & $47.6(9.8)$ & $45.5(7.8)$ & $47.6(9.0)$ & $46.9(8.8)$ \\
$(\min -\max )$ & $(35-54)$ & $(33-82)$ & $(32-67)$ & $(36-81)$ & $(32-82)$ \\
\hline
\end{tabular}

Data are presented as mean (standard deviation) unless otherwise noted

$C K D$ chronic kidney disease, $e G F R$ estimated glomerular filtration rate, TIBC total iron binding capacity, $T I W$ three times weekly, TSAT transferrin saturation

a Assessed at screening

b Individual patients were permitted to take more than one dose of oral iron

c Most patients had late stage 4 or early stage 5 N CKD based on eGFR values from KDIGO 2012 [3]

peak levels in the 70-mg and 100-mg groups and was a result of dose adjustments conducted to avoid any potential overshoot in Hb levels. When stratified by dosing frequency in the titration period (i.e., second randomization), both groups achieved target $\mathrm{Hb}$ levels; mean (SD) $\mathrm{Hb}$ levels at the end of treatment were $10.80(0.68) \mathrm{g} / \mathrm{dL}$ for those receiving roxadustat TIW and $10.42(0.61) \mathrm{g} / \mathrm{dL}$ for those receiving roxadustat QW (Fig. 4b).

\section{Exploratory Assessments}

The change from baseline to the EOF and end of treatment in ferritin, TSAT, hepcidin, TIBC, transferrin, and erythropoietin levels are shown in Table 3. Post hoc analyses showed a significant difference in all variables at EOF for the roxadustat TIW group compared with placebo TIW. No apparent trend was observed in time course of erythropoietin during the study, indicating that roxadustat can correct and maintain $\mathrm{Hb}$ levels with near physiologic levels of erythropoietin longitudinally (Table 3 ). Temporal data for ferritin, TSAT, hepcidin, and TIBC over the entire study are presented in the Supplementary Material (Figs. S1 and S2). The decrease in TSAT observed during the treatment period may indicate enhanced erythropoiesis, whereas the observed increase in TIBC may indicate improved iron-transporting capacity, as evidenced by the observed increase in transferrin. No patients received concomitant intravenous iron supplementation during the study; a total of 34 patients (placebo TIW, $n=7$; roxadustat $50 \mathrm{mg}$ TIW, $n=10$; roxadustat $70 \mathrm{mg}$ TIW, $n=8$; roxadustat $100 \mathrm{mg}$ TIW, $n=9$ ) received concomitant oral iron supplementation during the study (Table 1). Among patients who were receiving oral iron at baseline, 22 (placebo TIW, $n=5$; roxadustat $50 \mathrm{mg}$ TIW, $n=6$; roxadustat $70 \mathrm{mg}$ TIW, $n=7$; roxadustat $100 \mathrm{mg}$ TIW, $n=4$ ) continued oral iron throughout the treatment period.

\section{Clinical Laboratory Evaluations}

In the roxadustat TIW pooled group, mean serum cholesterol levels were reduced at week 4 (minimum value of $3.487 \mathrm{mmol} / \mathrm{L}$ [ $-1.020 \mathrm{mmol} / \mathrm{L}$ change from baseline]) and the mean serum ceruloplasmin levels increased (maximum value of $371.6 \mathrm{mg} / \mathrm{L} \quad[99.9 \mathrm{mg} / \mathrm{L}$ change from baseline]) compared with the placebo group. No notable differences between the treatment groups were observed in any other laboratory parameters.

\section{Safety and Treatment-Emergent Adverse Events}

The incidence of overall TEAEs ranged between $70.4 \%$ (placebo) and $88.5 \%$ (70 mg roxadustat); no deaths or major adverse cardiac events (i.e., myocardial infarction, stroke, death) occurred during the study (Table 4). Two cases of congestive heart failure (one with $50 \mathrm{mg}$ TIW and one with placebo) occurred during the study; 


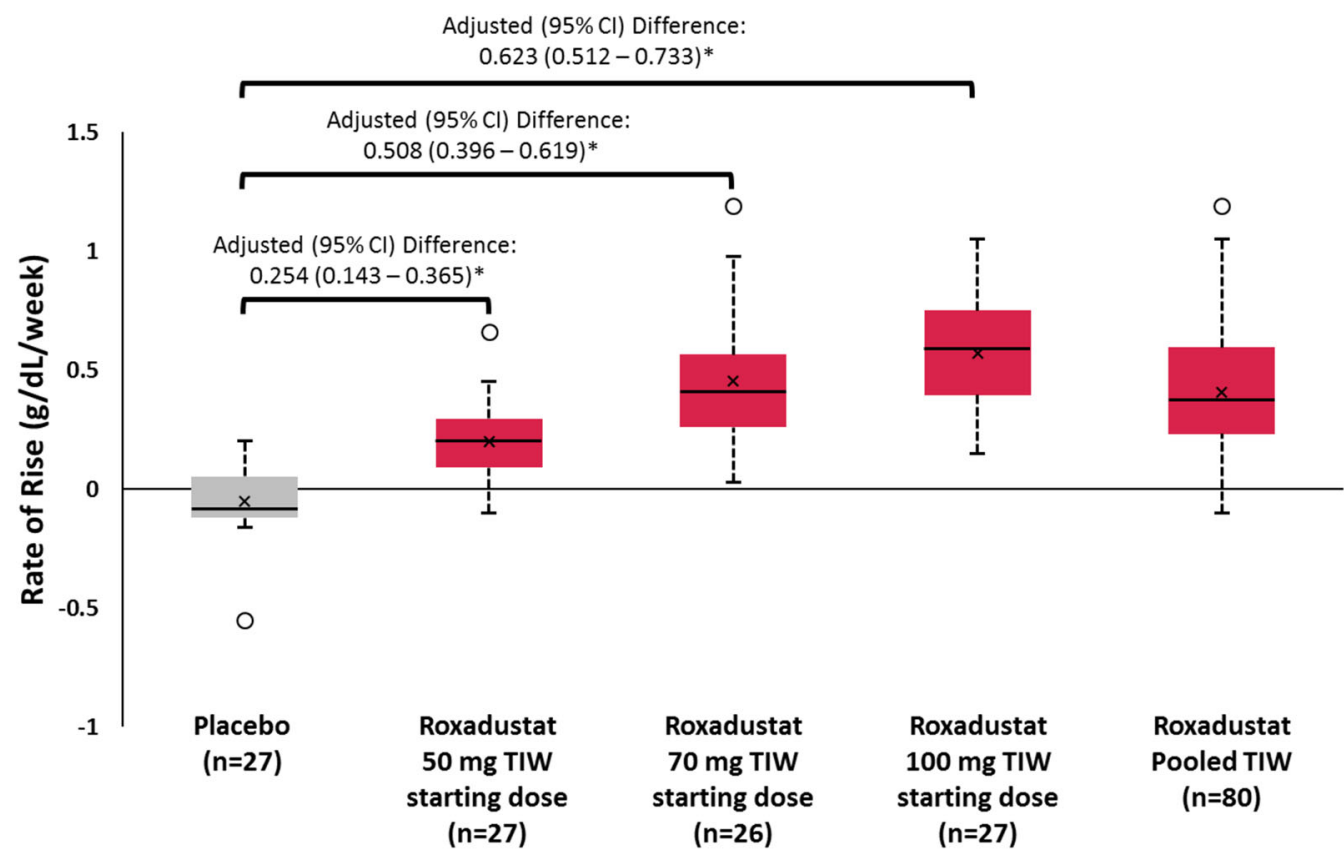

Fig. 3 Rate of rise in hemoglobin from baseline during the fixed-dose period (6 weeks). ${ }^{*} p<0.001$. Boxplots depict the interquartile range (box), mean $(\mathrm{x})$, median (black bar), range (whiskers), and outliers (circles); rate of rise in $\mathrm{Hb}$ was calculated as the slope of a linear regression for each

patient using all $\mathrm{Hb}$ data collected during the fixed-dose period. Data for the roxadustat TIW pooled group was the mean rate of rise in $\mathrm{Hb}$ for all roxadustat TIW-treated patients. Hb hemoglobin, TIW three times weekly

Table 2 Change in hemoglobin levels from baseline through week 4

\begin{tabular}{llllll}
\hline Variable & $\begin{array}{l}\text { Placebo } \\
\text { TIW } \\
(\boldsymbol{n}=\mathbf{2 7})\end{array}$ & $\begin{array}{l}\text { Roxadustat } \mathbf{5 0 ~} \mathbf{~ m g} \\
\text { TIW starting dose } \\
(\boldsymbol{n}=\mathbf{2 7})\end{array}$ & $\begin{array}{l}\text { Roxadustat 70 } \mathbf{~ m g} \\
\text { TIW starting dose } \\
(\boldsymbol{n}=\mathbf{2 6})\end{array}$ & $\begin{array}{l}\text { Roxadustat 100 mg } \\
\text { TIW starting dose } \\
(\boldsymbol{n}=\mathbf{2 7})\end{array}$ & $\begin{array}{l}\text { Roxadustat } \\
\text { TIW pooled } \\
(\boldsymbol{n}=\mathbf{8 0})\end{array}$ \\
\hline $\begin{array}{l}\text { Baseline } \\
\text { to }\end{array}$ & $\begin{array}{c}(0.19 \\
\text { week 2 }\end{array}$ & $0.45(0.48)$ & $1.01(0.61)$ & $1.20(0.71)$ & $0.89(0.68)$ \\
$\begin{array}{l}\text { Week 2 } \\
\text { to }\end{array}$ & -0.08 & $0.42(0.47)$ & $0.66(0.48)$ & $0.92(0.55)$ & \\
week 4 & $(0.49)$ & & & & $0.66(0.53)$ \\
\hline
\end{tabular}

Data are presented as mean (standard deviation)

$T I W$ three times weekly

the case in the placebo-treated patient was considered drug-related. In terms of clinically relevant arrhythmias, two cases of atrial fibrillation occurred (one with placebo and one with $70 \mathrm{mg}$ TIW).
The incidences of drug-related TEAEs, TEAEs leading to discontinuation, and serious TEAEs were below $20 \%$ in the placebo and 70 - and $100-\mathrm{mg}$ roxadustat TIW groups; the roxadustat $50-\mathrm{mg}$ TIW group had incidences of $37.0 \%$ for drug-related TEAEs, $29.6 \%$ for TEAEs leading to 

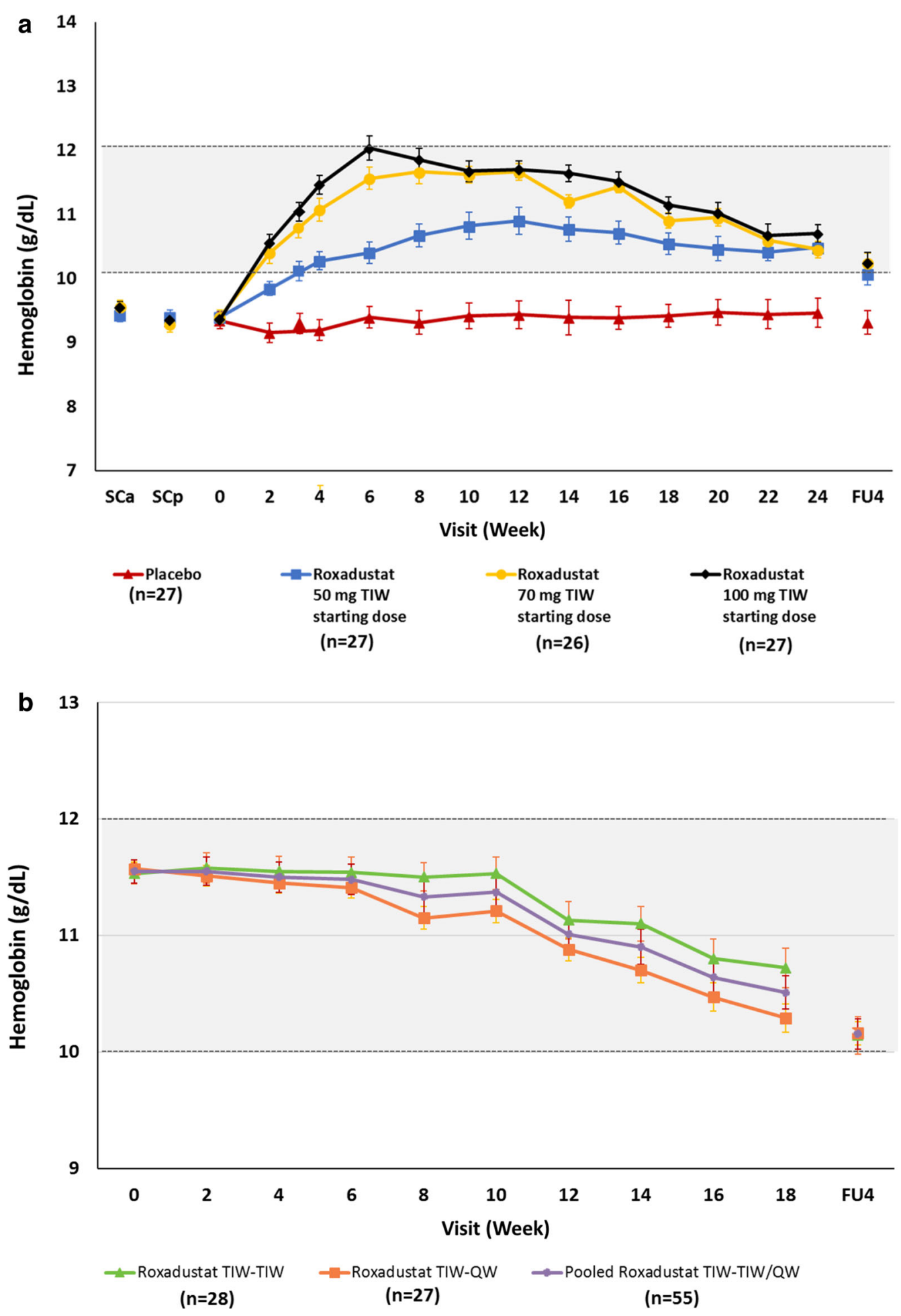

Fig. 4 Hemoglobin levels by week over the entire treatment period stratified by a dose during the fixed-dose period and $\mathbf{b}$ dosing frequency during the titration period. Data presented are mean \pm standard deviation. Grayed area represents the $\mathrm{Hb}$ target range of 10-12 g/dL. FU4 follow-up week 4, QW once weekly, SCa screening assessment, SCp screening period, TIW three times weekly 
Table 3 Change from baseline in serum ferritin, transferrin saturation, hepcidin, total iron binding capacity, transferrin, and erythropoietin by first randomization arm

\begin{tabular}{|c|c|c|c|c|c|}
\hline Variable & $\begin{array}{l}\text { Placebo } \\
\text { TIW } \\
(n=27)\end{array}$ & $\begin{array}{l}\text { Roxadustat } 50 \text { mg } \\
\text { TIW starting dose } \\
(n=27)\end{array}$ & $\begin{array}{l}\text { Roxadustat } 70 \mathrm{mg} \\
\text { TIW starting dose } \\
(n=26)\end{array}$ & $\begin{array}{l}\text { Roxadustat } 100 \mathrm{mg} \\
\text { TIW starting dose } \\
(n=27)\end{array}$ & $\begin{array}{l}\text { Roxadustat } \\
\text { TIW pooled } \\
(n=80)\end{array}$ \\
\hline \multicolumn{6}{|c|}{ Ferritin $(\mathrm{ng} / \mathrm{mL})$} \\
\hline $\begin{array}{l}\text { Change } \\
\text { from BL } \\
\text { to } \mathrm{EOF}^{\mathrm{a}}\end{array}$ & $\begin{array}{r}-10.3 \\
(23.2)\end{array}$ & $-52.7(24.5)^{\ddagger}$ & $-69.9(41.9)^{*}$ & $-69.9(37.8)^{*}$ & $-63.8(35.9)^{*}$ \\
\hline$p$ value & 0.03 & $<0.001$ & $<0.001$ & $<0.001$ & $<0.001$ \\
\hline $\begin{array}{l}\text { Change } \\
\text { from } \mathrm{BL} \\
\text { to } \mathrm{EOT}^{\mathrm{a}}\end{array}$ & $\begin{array}{r}-16.5 \\
(32.5)\end{array}$ & $-38.5(44.9)^{*}$ & $-23.4(52.7)$ & $-35.9(63.4)$ & $-32.7(53.9)$ \\
\hline$p$ value & 0.01 & $<0.001$ & 0.03 & 0.007 & $<0.001$ \\
\hline \multicolumn{6}{|l|}{ TSAT (\%) } \\
\hline $\begin{array}{l}\text { Change } \\
\text { from } \mathrm{BL} \\
\text { to } \mathrm{EOF}^{\mathrm{a}}\end{array}$ & $0.5(7.8)$ & $-6.4(9.7)^{\dagger}$ & $-7.7(15.0)^{*}$ & $-9.7(16.4)^{\dagger}$ & $-7.9(13.9)^{\dagger}$ \\
\hline$p$ value & 0.74 & 0.002 & 0.02 & 0.005 & $<0.001$ \\
\hline $\begin{array}{l}\text { Change } \\
\text { from } \mathrm{BL} \\
\text { to } \mathrm{EOT}^{\mathrm{a}}\end{array}$ & $0.2(10.2)$ & $-4.2(6.8)$ & $1.0(14.9)$ & $-0.2(13.3)$ & $-1.2(12.2)$ \\
\hline$p$ value & 0.90 & 0.004 & 0.73 & 0.93 & 0.40 \\
\hline \multicolumn{6}{|c|}{ Hepcidin (ng/mL) } \\
\hline $\begin{array}{l}\text { Change } \\
\text { from } \mathrm{BL} \\
\text { to } \mathrm{EOF}^{\mathrm{a}}\end{array}$ & $\begin{array}{r}-3.9 \\
(19.9)\end{array}$ & $-24.3(18.2)^{\ddagger}$ & $-36.1(26.3)^{*}$ & $-27.4(27.0)^{*}$ & $-29.2(24.3)^{*}$ \\
\hline$p$ value & 0.32 & $<0.001$ & $<0.001$ & $<0.001$ & $<0.001$ \\
\hline $\begin{array}{l}\text { Change } \\
\text { from } \mathrm{BL} \\
\text { to } \mathrm{EOT}^{\mathrm{a}}\end{array}$ & $2.4(39.6)$ & $-12.5(24.3)$ & $-3.3(31.9)$ & $-13.0(23.3)$ & $-9.7(26.7)$ \\
\hline$p$ value & 0.76 & 0.01 & 0.60 & 0.007 & 0.002 \\
\hline \multicolumn{6}{|c|}{$\operatorname{TIBC}(\mu \mathrm{mol} / \mathrm{L})$} \\
\hline $\begin{array}{l}\text { Change } \\
\text { from } \mathrm{BL} \\
\text { to } \mathrm{EOF}^{\mathrm{a}}\end{array}$ & $1.0(3.6)$ & $9.8(5.7)^{\ddagger}$ & $12.0(6.2)^{\ddagger}$ & $13.8(7.0)^{*}$ & $11.9(6.4)^{*}$ \\
\hline$p$ value & 0.16 & $<0.001$ & $<0.001$ & $<0.001$ & $<0.001$ \\
\hline
\end{tabular}


Table 3 continued

\begin{tabular}{|c|c|c|c|c|c|}
\hline Variable & $\begin{array}{l}\text { Placebo } \\
\text { TIW } \\
(n=27)\end{array}$ & $\begin{array}{l}\text { Roxadustat } 50 \mathrm{mg} \\
\text { TIW starting dose } \\
(n=27)\end{array}$ & $\begin{array}{l}\text { Roxadustat } 70 \mathrm{mg} \\
\text { TIW starting dose } \\
(n=26)\end{array}$ & $\begin{array}{l}\text { Roxadustat } 100 \mathrm{mg} \\
\text { TIW starting dose } \\
(n=27)\end{array}$ & $\begin{array}{l}\text { Roxadustat } \\
\text { TIW pooled } \\
(n=80)\end{array}$ \\
\hline $\begin{array}{l}\text { Change } \\
\text { from BL } \\
\text { to } \mathrm{EOT}^{\mathrm{a}}\end{array}$ & $0.9(3.9)$ & $9.2(8.4)^{\ddagger}$ & $4.6(8.9)$ & $6.1(6.5)^{*}$ & $6.7(8.1)^{*}$ \\
\hline$p$ value & 0.25 & $<0.001$ & 0.01 & $<0.001$ & $<0.001$ \\
\hline \multicolumn{6}{|c|}{ Transferrin $(\mathrm{g} / \mathrm{L})$} \\
\hline $\begin{array}{l}\text { Change } \\
\text { from } \mathrm{BL} \\
\text { to } \mathrm{EOF}^{\mathrm{a}}\end{array}$ & $0.02(0.1)$ & $0.5(0.3)^{\ddagger}$ & $0.6(0.3)^{*}$ & $0.7(0.3)^{*}$ & $0.6(0.3)^{*}$ \\
\hline$p$ value & 0.45 & $<0.001$ & $<0.001$ & $<0.001$ & $<0.001$ \\
\hline $\begin{array}{l}\text { Change } \\
\text { from BL } \\
\text { to } \mathrm{EOT}^{\mathrm{a}}\end{array}$ & $0.03(0.2)$ & $0.4(0.4)^{\ddagger}$ & $0.2(0.4)$ & $0.3(0.3)^{*}$ & $0.3(0.4)^{*}$ \\
\hline$p$ value & 0.39 & $<0.001$ & 0.02 & $<0.001$ & $<0.001$ \\
\hline \multicolumn{6}{|c|}{ Erythropoietin (IU/L) } \\
\hline $\begin{array}{l}\text { Change } \\
\text { from BL } \\
\text { to EOF }\end{array}$ & $\begin{array}{l}0.219 \\
\quad(1.804)\end{array}$ & $9.819(19.453)$ & $25.600(47.357)$ & $59.363(85.774)$ & $31.669(60.770)$ \\
\hline $\begin{array}{l}\text { Change } \\
\text { from BL } \\
\text { to EOT }\end{array}$ & $\begin{array}{l}0.444 \\
\quad(2.644)\end{array}$ & $23.807(114.180)$ & $14.192(69.717)$ & $19.837(79.420)$ & $19.343(88.996)$ \\
\hline
\end{tabular}

Data are presented as mean (standard deviation) unless otherwise noted. $p$ values were calculated by a $t$ test for the change from BL within group

$E O F$ final assessment in the fixed-dose period, EOT end of treatment, TIBC total iron binding capacity, TIW three times weekly, TSAT transferrin saturation

${ }^{*} p<0.05,{ }^{\dagger} p<0.01,{ }^{*} p<0.001$

a Significance was determined by a $t$ test for change from BL compared with placebo TIW

discontinuation, and $22.2 \%$ for serious TEAEs (Table 4). Discontinuation due to progressive disease requiring initiation of dialysis occurred in three patients $(11.1 \%)$ in the roxadustat 50-mg TIW group and one patient (3.7\%) in the roxadustat 100-mg TIW group. All four patients had baseline eGFR $\leq 10 \mathrm{~mL} / \mathrm{min} / 1.73 \mathrm{~m}^{2}$ and all four cases were considered by the investigator to be consistent with the natural progression of disease and therefore unrelated to the study drug. Discontinuation due to $\mathrm{Hb}$ level falling to $<8 \mathrm{~g} / \mathrm{dL}$ occurred in five patients treated with placebo, all of whom had baseline eGFR $\leq 17 \mathrm{~mL} / \mathrm{min} / 1.73 \mathrm{~m}^{2}$. Treatment-emergent adverse events occurring in $>5 \%$ of patients are presented in Table 4.

A total of six cases of declining kidney function were reported (placebo TIW, $n=1$; roxadustat $50 \mathrm{mg}$ TIW, $n=4$; roxadustat $100 \mathrm{mg}$ TIW, $n=1$ ), as indicated by elevated 
Table 4 Overview of treatment-emergent adverse events

\begin{tabular}{|c|c|c|c|c|c|}
\hline & $\begin{array}{l}\text { Placebo } \\
\text { TIW } \\
(n=27)\end{array}$ & $\begin{array}{l}\text { Roxadustat } 50 \mathrm{mg} \\
\text { TIW starting dose } \\
(n=27)\end{array}$ & $\begin{array}{l}\text { Roxadustat } 70 \mathrm{mg} \\
\text { TIW starting dose } \\
(n=26)\end{array}$ & $\begin{array}{l}\text { Roxadustat } 100 \mathrm{mg} \\
\text { TIW starting dose } \\
(n=27)\end{array}$ & $\begin{array}{l}\text { Roxadustat } \\
\text { TIW pooled } \\
(n=80)\end{array}$ \\
\hline Overall & $19(70.4)$ & $20(74.1)$ & $23(88.5)$ & $20(74.1)$ & $63(78.8)$ \\
\hline $\begin{array}{l}\text { Drug-related adverse } \\
\text { events }\end{array}$ & $4(14.8)$ & $10(37.0)$ & $4(15.4)$ & $5(18.5)$ & $19(23.8)$ \\
\hline Deaths & 0 & 0 & 0 & 0 & 0 \\
\hline $\begin{array}{l}\text { Adverse events leading to } \\
\text { discontinuation }\end{array}$ & $2(7.4)$ & $8(29.6)$ & 0 & $3(11.1)$ & $11(13.8)$ \\
\hline Serious adverse events & $2(7.4)$ & $6(22.2)$ & $2(7.7)$ & $3(11.1)$ & $11(13.8)$ \\
\hline $\begin{array}{l}\text { Drug-related serious } \\
\text { adverse events }\end{array}$ & 0 & $1(3.7)$ & 0 & $1(3.7)$ & $2(2.5)$ \\
\hline $\begin{array}{l}\text { Drug-related serious } \\
\text { adverse events leading } \\
\text { to discontinuation }\end{array}$ & $1(3.7)$ & $2(7.4)$ & 0 & $1(3.7)$ & $3(3.8)$ \\
\hline \multicolumn{6}{|c|}{$\begin{array}{l}\text { Treatment-emergent adverse events occurring in }>5 \% \text { of pooled roxadustat or placebo-treated patients by system organ } \\
\text { class preferred term }{ }^{\text {a }}\end{array}$} \\
\hline Gastrointestinal & $2(7.4)$ & $8(29.6)$ & $9(34.6)$ & $5(18.5)$ & $22(27.5)$ \\
\hline Diarrhea & $1(3.7)$ & $3(11.1)$ & $4(15.4)$ & $1(3.7)$ & $8(10.0)$ \\
\hline Nausea & 0 & $2(7.4)$ & $3(11.5)$ & 0 & $5(6.3)$ \\
\hline Infections/infestations & $9(33.3)$ & $7(25.9)$ & $14(53.8)$ & $11(40.7)$ & $32(40.0)$ \\
\hline Nasopharyngitis & $6(22.2)$ & $5(18.5)$ & $8(30.8)$ & $8(29.6)$ & $21(26.3)$ \\
\hline Renal/urinary disorders & $1(3.7)$ & $4(14.8)$ & 0 & $1(3.7)$ & $5(6.3)$ \\
\hline $\begin{array}{l}\text { Declining kidney } \\
\text { function }^{\mathrm{b}}\end{array}$ & $1(3.7)$ & $4(14.8)$ & 0 & $1(3.7)$ & $5(6.3)$ \\
\hline $\begin{array}{l}\text { Musculoskeletal and } \\
\text { connective tissue } \\
\text { disorders }\end{array}$ & $4(14.8)$ & $3(11.1)$ & $4(15.4)$ & $4(14.8)$ & $11(13.8)$ \\
\hline Muscle spasms & $2(7.4)$ & 0 & $1(3.8)$ & 0 & $1(1.3)$ \\
\hline $\begin{array}{l}\text { Respiratory, thoracic, and } \\
\text { mediastinal disorders }\end{array}$ & $2(7.4)$ & $2(7.4)$ & $2(7.7)$ & $1(3.7)$ & $5(6.3)$ \\
\hline Cough & $2(7.4)$ & 0 & 0 & $1(3.7)$ & $1(1.3)$ \\
\hline
\end{tabular}

Data are presented as number (\%) of patients More than one $\mathrm{AE}$ can be reported per patient

${ }^{a}$ Medical Dictionary for Regulatory Activities (MedDRA) version 15.1

b All patients with declining kidney function had a mean eGFR $\leq 11 \mathrm{~mL} / \mathrm{min} / 1.73 \mathrm{~m}^{2}$ at baseline 
blood urea nitrogen and/or creatinine levels. None of the six cases were related to the study drug but were considered to reflect the natural course of CKD or an effect of a concomitant medication (i.e., loxoprofen). Of these cases, four required dialysis treatment during the study and therefore led to withdrawal, one completed the study and initiated dialysis treatment afterwards, and one case occurred 1 month after withdrawal of the study and was reported by the investigator to be due to administration of loxoprofen. All six patients with declining kidney function had eGFR $\leq 11 \mathrm{~mL} / \mathrm{min} / 1.73 \mathrm{~m}^{2}$ at baseline and had diabetic nephropathy $(n=4)$ or nephrosclerosis $(n=2)$ as the underlying cause of disease.

Two cases of hepatic dysfunction occurred in patients treated with placebo TIW. Both resolved following discontinuation of treatment, and neither were considered by the investigator to be related to the study drug. No abnormal hepatic function was reported in roxadustat-treated patients.

No significant changes were observed in the mean values of systolic blood pressure, diastolic blood pressure, or pulse rate in the placebo and roxadustat groups.

\section{DISCUSSION}

Treatment with roxadustat in this study resulted in a dose-dependent and significant correction of $\mathrm{Hb}$ compared with placebo within 6 weeks of treatment initiation. The rate of rise in $\mathrm{Hb}$ as the primary end point is a unique aspect of this study and represents the first report of these data collected prospectively. Given the potential safety risks of a rapid increase in $\mathrm{Hb}$ demonstrated by a higher rate of cardiovascular adverse events with increasing doses of ESAs [5, 6, 19-21], the Guidelines for Renal Anemia in Chronic Kidney Disease set forth by the Japanese Society for Dialysis Therapy recommend that $\mathrm{Hb}$ level should not increase at a rate exceeding $0.5 \mathrm{~g} / \mathrm{dL} /$ week [22]. This study was designed to quantify the rate of rise in $\mathrm{Hb}$ with various starting doses of roxadustat. While the mean rate of rise in $\mathrm{Hb}$ did not exceed $0.5 \mathrm{~g} / \mathrm{dL} /$ week with roxadustat administered at both $50 \mathrm{mg}$ and $70 \mathrm{mg}$ TIW (Fig. 3), a total of 25 (31.3\%) patients exceeded this threshold (roxadustat $50 \mathrm{mg}$ TIW, $n=1$; roxadustat $70 \mathrm{mg}$ TIW, $n=9 ;$ roxadustat $100 \mathrm{mg}$ TIW, $n=15$ ). Furthermore, the US Food and Drug Administration placed safety warnings on the labels for epoetin alfa and darbepoetin alfa to reduce dosage by $25 \%$ or more if $\mathrm{Hb}$ rises at a rate greater than $1 \mathrm{~g} / \mathrm{dL}$ in any 2 -week period $[23,24]$. The 50 - and 70 -mg doses of roxadustat also did not exceed this threshold, whereas the mean (SD) rate of rise in the 100-mg TIW group exceeded this threshold during the fixed-dose period $(0.570$ [0.240] $\mathrm{g} / \mathrm{dL} /$ week), indicating a potential overshoot in $\mathrm{Hb}$ correction with the 100-mg dose (Table 2).

Similar anemia correction with roxadustat TIW in NDD-CKD patients has been reported in prior phase 2 studies conducted in different regions (USA and China). In a phase $2 b$ study [14], 92\% of 143 patients in the USA and Puerto Rico achieved $\mathrm{Hb}$ response ( $\mathrm{Hb}$ increase of $\geq 1 \mathrm{~g} / \mathrm{dL}$ ), and the time to $\mathrm{Hb}$ response varied by dose. In another phase 2 a study in the USA [13], $\mathrm{Hb}$ response was achieved by $91 \%$ of patients treated with roxadustat $1.5 \mathrm{mg} / \mathrm{kg}$ TIW and $100 \%$ of patients treated with roxadustat $2.0 \mathrm{mg} / \mathrm{kg}$ TIW; the change from baseline in $\mathrm{Hb}$ $(\mathrm{g} / \mathrm{dL})$ at 6 weeks was +1.2 and +1.8 for $1.5 \mathrm{mg} / \mathrm{kg}$ and $2.0 \mathrm{mg} / \mathrm{kg}$, respectively. In a recent phase 2 study of NDD-CKD patients in China [15], Hb response was achieved in $80.0 \%$ and $87.1 \%$ of patients receiving low dose $(1.1-1.8 \mathrm{mg} / \mathrm{kg})$ and high dose $(1.7-2.3 \mathrm{mg} / \mathrm{kg})$ roxadustat, respectively. This consistency of results observed among populations in the USA, China, and now Japan indicates uniformity in response across diverse ethnic groups.

Our results are also consistent with phase 2 studies showing that treatment with roxadustat decreased serum hepcidin [13-15], which is commonly elevated in CKD patients. In the present study, Hb levels increased without rendering patients functionally or absolutely iron deficient, and $33.8 \%$ of patients receiving roxadustat received oral iron during the study. This finding is consistent with several phase 2 studies demonstrating that roxadustat increases $\mathrm{Hb}$ in a dose-dependent manner without intravenous iron supplementation. 
The current study does have limitations. While the sample size and treatment duration were sufficient to demonstrate a treatment benefit, larger clinical studies of longer duration will provide safety and tolerability data associated with longer-term treatment with roxadustat and allow for the recommendation of appropriate dose and frequency of administration. The differential dropout rates for roxadustat- and placebo-treated patients should also be considered, particularly when interpreting the safety results of this study. Several larger phase 3 trials are ongoing (Clinicaltrials.org \# NCT02021318, NCT02273726, NCT02174731, NCT01887600, NCT02174627, NCT02278341, NCT02052310, NCT01750190, NCT01630889). Notable differences in the Japanese patients in our study were a low mean (SD) baseline body weight $(59 \pm 10 \mathrm{~kg})$ and low mean body mass index $\left(24 \pm 3 \mathrm{~kg} / \mathrm{m}^{2}\right)$ compared with roxadustat studies in the USA and China, where mean body weight was $>60-90 \mathrm{~kg}[14,16,17]$. Furthermore, the mean age of 64.4 years and the extensive exclusion criteria in this population of Japanese patients may limit the generalizability of these results to younger populations in other regions or those with comorbidities. However, results from the current study are comparable with previous phase 2 studies in larger populations $[14,16,17]$.

\section{CONCLUSION}

The results from this phase 2 study demonstrate safe and dose-dependent correction of $\mathrm{Hb}$ in anemic Japanese NDD-CKD patients and support further investigation in phase 3 studies of oral roxadustat for the treatment of anemia associated with NDD-CKD.

\section{ACKNOWLEDGEMENTS}

The authors would like to thank all study participants and their families. Data collection, hepcidin measurement, and statistical analyses were conducted by Astellas. Clinical laboratory analyses were performed by SRL Medisearch Inc. (Tokyo, Japan).

Funding. This study, the article processing charges, and the Open Access fee were sponsored and monitored by Astellas Pharma Inc. Roxadustat is being developed by Astellas Pharma, FibroGen, and AstraZeneca.

Medical Writing and Editorial Assistance. Financial support for this manuscript, including writing and editorial assistance by OPEN Health Medical Communications (Chicago, IL), was provided by Astellas Pharma Inc.

Authorship. All named authors meet the International Committee of Medical Journal Editors (ICMJE) criteria for authorship for this article, take responsibility for the integrity of the work as a whole, and have given their approval for this version to be published. All authors had full access to all of the data in this study and take complete responsibility for the integrity of the data and accuracy of the data analysis.

Authorship Contributions. Tadao Akizawa, Tetsuro Otsuka, Michael Reusch, and Toshihiro Misumi contributed to the conception or design of the work and analysis and interpretation of the data. Manabu Iwasaki contributed to the analysis and interpretation of the data. All authors contributed to drafting and revising of the manuscript, provided intellectual content of critical importance, and approved the final version of the manuscript to be submitted for publication.

Disclosures. Tadao Akizawa reports personal fees from Astellas during the conduct of the study, and personal fees from Kyowa Hakko Kirin, AbbVie Inc., JT Pharmaceuticals Corporate, Kissei Pharmaceutical, Nipro Medical, Ono Pharmaceutical, Bayer HealthCare, Chugai Pharmaceutical, Torii Pharmaceutical, Fuso Pharmaceutical, Teijin Pharma, and GlaxoSmithKline outside the submitted work. Michael Reusch is employed with Astellas Pharma Europe B.V. Tetsuro Otsuka is employed with Astellas Pharma Inc. Toshihiro Misumi was 
employed with Astellas Pharma Inc. during the conduct of the study. Manabu Iwasaki has nothing to disclose.

Compliance with Ethics Guidelines. This study (ClinicalTrials.gov identifier, NCT01964196) was conducted in accordance with the Declaration of Helsinki and was approved by the following institutional review boards: Tokushukai Group Institutional Review Board; Institutional Review Board of Yokosuka Kyosai Hospital; Review Board of Human Rights and Ethics for Clinical Studies; Institutional Review Board of Chubu Rosai Hospital; Institutional Review Board of Kawashima Hospital; Institutional Review Board of Kinashi Obayashi Hospital; Institutional Review Board of Hyogo Prefectural Amagasaki General Medical Center; Institutional Review Board of Rinku General Medical Center; Institutional Review Board of Ehime Prefectural Central Hospital; Institutional Review Board of Juntendo Tokyo Koto Geriatric Medical Center; Institutional Review Board of NTT Medical Center Tokyo; Institutional Review Board of Takikawa Municipal Hospital; National Hospital Organization Central Review Board; Institutional Review Board of Kitamachi clinic; Institutional Review Board of Rakuwakai Otowa Hospital; Institutional Review Board of Fukui Prefectural Hospital; Institutional Review Board of Southern Tohoku Research Institute for Neuroscience; Institutional Review Board of Kitano Hospital; Sapporo Skin Clinic Institutional Review Board; Institutional Review Board of Nagano Red Cross Hospital; Institutional Review Board of Tsuchiura Kyodo General Hospital. All patients provided written informed consent.

Data Availability. Studies conducted with product indications or formulations that remain in development are assessed after study completion to determine if Individual Participant Data can be shared. The plan to share Individual Participant Data is based on the status of product approval or termination of the compound, in addition to other study-specific criteria described on www.clinicalstudydatarequest.com under "Sponsor Specific Details for Astellas."
Open Access. This article is distributed under the terms of the Creative Commons Attribution-NonCommercial 4.0 International License (http://creativecommons.org/licenses/ by-nc/4.0/), which permits any noncommercial use, distribution, and reproduction in any medium, provided you give appropriate credit to the original author(s) and the source, provide a link to the Creative Commons license, and indicate if changes were made.

\section{REFERENCES}

1. KDOQI National Kidney Foundation. KDOQI clinical practice guidelines and clinical practice recommendations for anemia in chronic kidney disease. Am J Kidney Dis. 2006;47(5 Suppl 3):S11-145.

2. Akizawa T, Okumura $\mathrm{H}$, Alexandre AF, et al. Burden of anemia in chronic kidney disease patients in Japan: a literature review. Ther Apher Dial. 2018;22(5):444-56.

3. Kidney Disease: Improving Global Outcomes (KDIGO) Anemia Work Group. KDIGO clinical practice guideline for anemia in chronic kidney disease. Kidney Int Suppl. 2012;2(4):279-335.

4. Krapf R, Hulter HN. Arterial hypertension induced by erythropoietin and erythropoiesis-stimulating agents (ESA). Clin J Am Soc Nephrol. 2009;4(2):470-80.

5. Pfeffer MA, Burdmann EA, Chen CY, et al. A trial of darbepoetin alfa in type 2 diabetes and chronic kidney disease. N Engl J Med. 2009;361(21):2019-32.

6. Singh AK, Szczech L, Tang KL, et al. Correction of anemia with epoetin alfa in chronic kidney disease. N Engl J Med. 2006;355(20):2085-98.

7. Locatelli F, Fishbane S, Block GA, Macdougall IC. Targeting hypoxia-inducible factors for the treatment of anemia in chronic kidney disease patients. Am J Nephrol. 2017;45(3):187-99.

8. Haase VH. Regulation of erythropoiesis by hypoxiainducible factors. Blood Rev. 2013;27(1):41-53.

9. Peyssonnaux C, Zinkernagel AS, Schuepbach RA, et al. Regulation of iron homeostasis by the hypoxia-inducible transcription factors (HIFs). J Clin Invest. 2007;117(7):1926-32. 
10. Fandrey J. Oxygen-dependent and tissue-specific regulation of erythropoietin gene expression. Am J Physiol Regul Integr Comp Physiol. 2004;286(6):R977-88.

11. Souma T, Nezu M, Nakano D, et al. Erythropoietin synthesis in renal myofibroblasts is restored by activation of hypoxia signaling. J Am Soc Nephrol. 2016;27(2):428-38.

12. Tsuchiya K, Nitta K. Hepcidin is a potential regulator of iron status in chronic kidney disease. Ther Apher Dial. 2013;17(1):1-8.

13. Besarab A, Provenzano R, Hertel J, et al. Randomized placebo-controlled dose-ranging and pharmacodynamics study of roxadustat (FG-4592) to treat anemia in nondialysis-dependent chronic kidney disease (NDD-CKD) patients. Nephrol Dial Transplant. 2015;30(10):1665-73.

14. Provenzano R, Besarab A, Sun $\mathrm{CH}$, et al. Oral hypoxia-inducible factor prolyl hydroxylase inhibitor roxadustat (FG-4592) for the treatment of anemia in patients with CKD. Clin J Am Soc Nephrol. 2016;11(6):982-91.

15. Chen N, Qian J, Chen J, et al. Phase 2 studies of oral hypoxia-inducible factor prolyl hydroxylase inhibitor FG-4592 for treatment of anemia in China. Nephrol Dial Transpl. 2017;32(8):1373-86.

16. Besarab A, Chernyavskaya E, Motylev I, et al. Roxadustat (FG-4592): correction of anemia in incident dialysis patients. J Am Soc Nephrol. 2016;27(4):1225-33.

17. Provenzano R, Besarab A, Wright S, et al. Roxadustat (FG-4592) versus epoetin alfa for anemia in patients receiving maintenance hemodialysis: a phase 2, randomized, 6- to 19-week, open-label, active-comparator, dose-ranging, safety and exploratory efficacy study. Am J Kidney Dis. 2016;67(6):912-24.

18. Matsuo S, Imai E, Horio M, et al. Revised equations for estimated GFR from serum creatinine in Japan. Am J Kidney Dis. 2009;53(6):982-92.

19. Singh AK. The FDA's perspective on the risk for rapid rise in hemoglobin in treating CKD anemia: quo vadis. Clin J Am Soc Nephrol. 2010;5(4):553-6.

20. Besarab A, Bolton WK, Browne JK, et al. The effects of normal as compared with low hematocrit values in patients with cardiac disease who are receiving hemodialysis and epoetin. $\mathrm{N}$ Engl $\mathrm{J}$ Med. 1998;339(9):584-90.

21. Unger EF, Thompson AM, Blank MJ, Temple R. Erythropoiesis-stimulating agents-time for a reevaluation. N Engl J Med. 2010;362(3):189-92.

22. Tsubakihara Y, Nishi S, Akiba T, et al. 2008 Japanese Society for Dialysis Therapy: guidelines for renal anemia in chronic kidney disease. Ther Apher Dial. 2010;14(3):240-75.

23. Epogen $^{\circledR}$ (epoetin alfa) [Full prescribing information]. Amgen Inc. Thousand Oaks, CA; 2012. http:// pi.amgen.com/united_states/epogen/epogen_pi_hcp_ english.pdf). Accessed 19 Oct 2016.

24. Aranesp ${ }^{\circledR}$ (darbepoetin alfa) [Full prescribing information]. Amgen Inc. Thousand Oaks, CA; 2015. http://pi.amgen.com/ /media/amgen/repository sites/pi-amgen-com/aranesp/ckd/aranesp_pi_hcp_ english.ashx). Accessed 24 Jan 2017. 